\title{
Electrochemical Surface Oxidation of Copper Studied by in Situ Grazing Incidence X-ray Diffraction
}

\author{
Michael Scherzer, ${ }^{\dagger \neq}$ Frank Girgsdies, ${ }^{\ddagger}$ Eugen Stotz, ${ }^{\ddagger}$ Marc-Georg Willinger, ${ }^{\ddagger}{ }^{\circledR}$ (0) Elias Frei, ${ }^{\ddagger}$ (i) \\ Robert Schlögl, ${ }^{\dagger,+\infty}$ Ullrich Pietsch," and Thomas Lunkenbein*, ${ }^{*}+\mathbb{0}$
}

${ }^{\dagger}$ Department of Heterogeneous Reactions, Max Planck Institute for Chemical Energy Conversion, Stiftstrasse 34-36, 45470 Mülheim a. d. Ruhr, Germany

${ }^{\ddagger}$ Department of Inorganic Chemistry, Fritz-Haber-Institut der Max-Planck-Gesellschaft, Faradayweg 4-6, 14195 Berlin, Germany

${ }^{\S}$ Scientific Center for Optical and Electron Microscopy, ScopeM, ETH Zürich, Otto-Stern-Weg 3, 8093 Zurich, Switzerland

"Institute of Physics, Emmy-Noether-Campus, University of Siegen, Walter-Flex-Strasse 3, 57072 Siegen, Germany

Supporting Information

ABSTRACT: Grazing incidence X-ray diffractometry (GIXRD) can deliver integral information on the structure and chemistry of surface near regions, which can be beneficial for functional materials related to interfacial reactions. Here, we present an in situ laboratory GIXRD setup for electrochemical experiments. The method is capable of directly correlating changes of the crystalline surface structure to the electrochemical conditions. It combines cyclovoltametric (CV) and chronoamperometric (CA) curves of crystalline samples, which can be recorded over the entire $\mathrm{pH}$ range, with simultaneous GIXRD measurements. The stepwise oxidation of polycrystalline copper in alkaline medium acts as an example to prove the functionality of the setup. In situ GIXRD measurements during CA experiments reveal a stepwise oxidation mechanism of metallic $\mathrm{Cu}$ to $\mathrm{Cu}^{2+}$ involving crystalline cuprite $\left(\mathrm{Cu}_{2} \mathrm{O}\right)$ intermediates. The results highlight the importance of conducting in situ experiments under controlled environments in order to track transient states even for a comparable simple oxidation reaction.

\section{INTRODUCTION}

In situ investigations of functional materials play an important analytical role in material science such as cancer research, metallurgy, or catalysis. In catalysis research, for instance, in situ measurements allow for establishing a direct correlation between structural modifications and the performance of the material as a function of the chemical potential. Various diffraction techniques are often conducted in situ to unravel the dynamic behavior of the crystalline bulk structure. ${ }^{1}$ These measurements may be performed at synchrotrons or in the laboratory. ${ }^{1-5}$ Synchrotron beam time, however, is expensive. Successful beam time applications require time, patience, and usually a sound understanding of the catalytic reaction and the sample. As opposed to synchrotron radiation, laboratory X-ray sources are widespread. However, low photon flux and collimated beams compared to synchrotron radiation may limit the use of laboratory X-ray sources for in situ experiments. ${ }^{6}$ However, the lower beam flux of a lab source would be beneficial to investigate metastable surfaces as it prevents radiolysis and other beam-induced effects, which can appear in high-brilliance sources and would otherwise overstress the analysis of relevant working surfaces. Thus, research that focuses on the development of laboratory-based in situ diffraction setups has to be further exploited. Such new setups for different X-ray scattering techniques can act as cheap and available alternatives or as screening capabilities to explore new approaches.

In particular, for grazing incidence X-ray diffraction (GIXRD) experiments, parameters such as photon flux and beam collimation are of paramount importance, as the intensity of the diffracted wave is on the order of $10^{-8}$ counts per second. ${ }^{6}$ These restrictions of laboratory diffractometers could be decreased by the development of modern X-ray optics, such as "Göbel mirrors". In GIXRD the penetration depth of the incoming beam can be precisely controlled. ${ }^{8}$ Even monolayers on single crystalline surfaces can be investigated with this technique. ${ }^{9,10}$ As opposed to local transmission electron microscopy (TEM), GIXRD measurements can provide integral nondestructive information on a crystalline surface.

Integral information on surface structures and their modifications are important aspects toward a detailed under-

Received: January 10, 2019

Revised: $\quad$ May 3, 2019

Published: May 6, 2019 
standing of electrochemical processes. In electrochemistry, the electrode is immersed in an electrolyte, forming a solidelectrolyte interface. This interface dictates the electron exchange between electrode and electrolyte, and modulates the rate of electrochemical reactions. ${ }^{11-13}$ Previous results have suggested that surface-sensitive diffraction techniques are powerful enough to investigate the near-surface structures of electrode materials. ${ }^{13}$ However, important insights into the relevant surface structure at the solid-electrolyte interface under working conditions are often missing. These insights would be fundamental in establishing new structure-activity correlations.

Here, we present an in situ electrochemical cell for measuring crystalline surfaces that is based on a laboratory GIXRD setup. To show the working principle, we focus on the electrochemical oxidation of polycrystalline copper in alkaline media. Many details on the electrochemical oxidation mechanism of copper in alkaline media are still not clarified. The formation of oxidic surface layers on copper changes its environmental stability and has been studied extensively since the pioneering electrochemical work of Müller. ${ }^{14}$ Detailed knowledge on the oxidation mechanism of $\mathrm{Cu}$ is important, as $\mathrm{Cu}$ is utilized in a huge variety of different technologies. ${ }^{15}$ For instance, in renewable energy research $\mathrm{Cu}$ is used as electrode material for the electrochemical reduction of $\mathrm{CO}_{2}$ toward multicarbon alcohol and hydrocarbon species. ${ }^{16-18}$ In this reaction the oxidation state of $\mathrm{Cu}$ modulates the electrochemical performance and determines its long-term stability. This underlines the scientific importance to unravel details of the oxidation and reduction behavior of $\mathrm{Cu}$.

In order to elucidate details of the oxidation state of the active phase operando investigations of surface species are needed. To date, integral changes of the surface are mainly tracked by X-ray photoelectron spectroscopy (XPS). In this view, the electrochemical oxidation of $\mathrm{Cu}$ has been studied in acidic media by in situ XPS. ${ }^{19}$ This study observed $\mathrm{Cu}^{+}$species after electrodeposition on an $\mathrm{Au}$ substrate. These $\mathrm{Cu}^{+}$species tend to form oxyhydroxide species. During acidic aging condensation and oxidation to $\mathrm{CuO}$ occur, which can subsequently be dissolved under this condition as $\mathrm{Cu}^{2+}$ species. These results further suggest that the condensation chemistry of $\mathrm{Cu}$ species under dynamic reaction conditions are part of kinetically driven solid-liquid interfacial processes.

The presented in situ electrochemical GIXRD approach can prospectively complement in situ XPS investigations by pinpointing crystalline surface phases under working conditions. As we will show by this in situ study, cuprite $\left(\mathrm{Cu}_{2} \mathrm{O}\right)$ is an important intermediate in the electrochemical oxidation of $\mathrm{Cu}$ in alkaline media.

\section{EXPERIMENTAL SECTION}

In Situ Setup. In general, GIXRD analysis of thin films can be divided into two groups: in-plane and out-of-plane measurements. In-plane measurements are based on an almost $90^{\circ}$ inclination of the sample surface to its surface normal. The sample tilt allows for testing lattice planes that are normal to the surface of the thin film. This method is beneficial for textured samples and requires a sound preknowledge of the film. Owing to the $90^{\circ}$ inclination, in situ in-plane measurements combined with electrochemical setups are challenging. Depth profiling of thin films by GIXRD can be achieved by the out-of-plane technique. As opposed to in-plane GIXRD measurements, the tested lattice planes are analyzed parallel to the sample surface. In this technique, the penetration depth is controlled by the incidence angle $\left(\alpha_{\mathrm{i}},<1^{\circ}\right)$ of the X-ray beam with respect to the sample surface. An out-of-plane in situ setup for electrochemical investigations would allow for a fast and facile exchange of the electrolyte, electrodes, or reaction parameters, and would generate sufficient beam flux to study polycrystalline samples in situ with laboratory X-ray sources.

The developed in situ cell for out-of-plane GIXRD measurements on laboratory X-ray diffractometers is shown in Figure 1 and exhibits a total volume of approximately 7.5

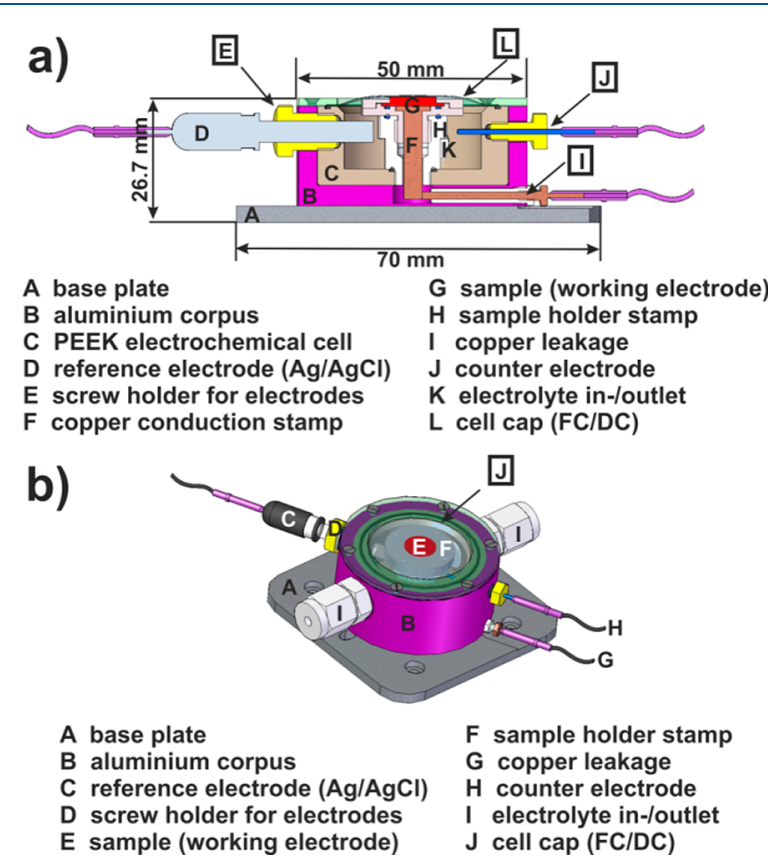

Figure 1. In situ XRD cell that was optimized for grazing incidence diffraction at different orientations: (a) cross section and (b) side view.

$\mathrm{mL}$. The cell consists of three main parts: an aluminum corpus (Figure 1a, part B; 1b, part B) which hosts an electrochemical PEEK cell (poly(ether ether ketone), Figure 1a, part C) and an $\mathrm{X}$-ray transparent window (Figure 1a, part L; 1b, part J). PEEK exhibits a high chemical inertness against the majority of acidic and alkaline electrolytes and is, therefore, frequently chosen for the construction of electrochemical devices. ${ }^{20}$ In addition, the in- and outlet of the electrolyte are manufactured from PEEK and are connected via Teflon hoses and PEEK ball-valves (Figure $\mathrm{S} 1$, part $\mathrm{A} / \mathrm{B}$ ). The $\mathrm{Ag} / \mathrm{AgCl}$ reference electrode (Biologic RE-1S, Figure 1a, part D; $1 b$, part C) is fixed by a PEEK nut and sealed with a Viton O-ring. In addition, a Ptwire counter electrode $(1 \mathrm{~mm}$ diameter, $\sim 10 \mathrm{~mm}$ exposed length inside the cell to ensure a similar surface area than the working electrode) was placed opposite of the reference electrode. The PEEK working electrode holder was tailored to fit hat-shaped substrates (Figure S2, part E). A hat-shaped substrate (step height: $0.7 \mathrm{~mm}$, exposed surface diameter: 10 $\mathrm{mm}$ ) allows for enhancing the mounting strength. Furthermore, a continuous rim $(13.5 \mathrm{~mm})$ provides a solid platform to fix the sample and to seal the leakage, while the surface of the sample can be easily exposed to the electrolyte and the X-ray beam. The bottom of the sample is contacted by a $\mathrm{Cu}$ stamp and sealed by a Viton O-ring (Figure S2, Part B). Finally the 
three electrode setup is realized by contacting the $\mathrm{Cu}$ stamp with a $\mathrm{Cu}$ rod screwed (Figure 1a, part I; 1b, part $\mathrm{G}$ ) through the $\mathrm{Al}$ corpus. The cell can be filled with the chosen electrolyte by attaching a syringe. The dead volume of the setup is approximately $6.5 \mathrm{~mL}$ (Figure S1) and depends on the cap used. In the present work, the cell was used without any flow.

The setup of the in situ cell was optimized for a Bruker D8 Advance diffractometer (da Vinci design) combined with the compact Eulerian cradle sample stage. An Eulerian cradle ensures an optimum alignment of the surface of the sample using the $\varphi$ - and $\chi$-circles. In addition, the cradle ensures a fine-tuning of the sample height in the $\mu \mathrm{m}$ range. Similar results were obtained with a $x y z$-stage. However, the common $x y z$-stage offers fewer degrees of freedom, which could be a bottleneck during adjusting the surface parallel to the X-ray beam. Moreover, GIXRD requires unimpeded access to the sample surface in order to avoid measurement artifacts from the sample holder. Thus, the sample is fixed at the highest point of the setup.

The most important part for tracking electrochemical reactions in situ by X-ray diffraction is the X-ray transparent window, i.e., the cell cap. The in situ cell can be operated either "foil capped" (FC) or "dome capped" (DC). The foil cap is composed of Kapton (foil thickness: $7.5 \mu \mathrm{m}$ ) and mounted by a poly(methyl methacrylate) (PMMA) ring onto the PEEK cell. Kapton exhibits a very low linear absorption coefficient and chemical inertness. The $0.7 \mathrm{~mm}$ thick dome cap is made from PMMA and is hemispherical in shape (diameter: 32 $\mathrm{mm}$ ). PMMA guarantees the stability of the hemispherical shape. Figure 2 displays two different types of caps. These two caps differ in the amount of the electrolyte immersing the surface.

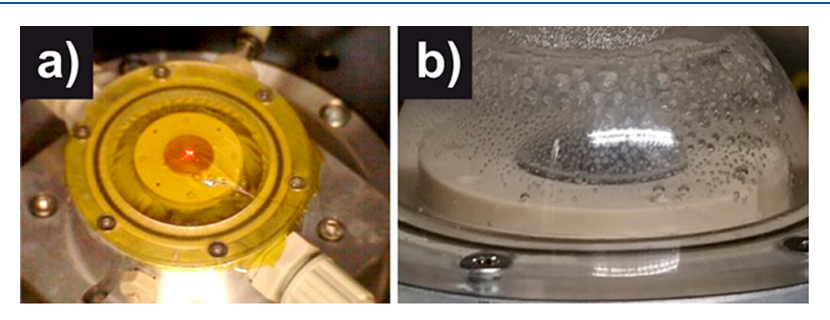

Figure 2. Photographs of the different operation modes: (a) foil capping (FC) and (b) dome capping (DC).

The FC setup (Figure 2a) is beneficial for polycrystalline samples. The sample is exposed to a thin electrolyte layer (thickness: $\sim 300-500 \mu \mathrm{m}$ ). Owing to the small coherence length of the different grains, polycrystalline samples require a high intensity of the X-ray beam which can be best obtained by a thin electrolyte layer. The FC mode combines optimized diffraction conditions with the quality of electrochemical measurements. In the DC setup (Figure 2b) the sample is exposed to a larger amount of electrolyte. The high amount of electrolyte prevents space limiting diffusion of the charge carriers. However, if the DC setup is used for diffractive measurements, the electrolyte content has to be lowered until a meniscus remains on top of the sample. Thus, prior to the experiments, blind tests shall be conducted with either a sample dummy or an inert liquid to find empirically the optimum meniscus level for each sample. The DC mode is considered for single crystalline samples or samples with a very well-defined and flat surface, where diffusion limitations can be avoided.
The in situ setup is further capable of performing symmetric scans (e.g., Bragg-Brentano), out-of-plane GIXRD measurements, and reciprocal space mapping (RSM). The present work focuses on surface-sensitive GIXRD measurements in the FC mode. For this GIXRD investigation, low surface roughness is beneficial.

Electrochemical Oxidation of Copper in Alkaline Media. The copper sample was cut from a massive copper piece (hat-shaped substrate with a step height of $0.7 \mathrm{~mm}$, exposed surface diameter of $10 \mathrm{~mm}$ and a $13.5 \mathrm{~mm}$ rim) and was subsequently polished with $\mathrm{SiC} 2400$ sand paper to achieve a shiny surface (10 $\mathrm{mm}$ diameter). Prior to the measurement the electrode was kept for $10 \mathrm{~min}$ at $-1 \mathrm{~V}$ to remove intrinsic surface oxides.

Electrochemical experiments were performed in $0.2 \mathrm{M} \mathrm{KOH}$ (ultrapure Merck) and purged with Argon. Pt wire and $\mathrm{Ag} /$ $\mathrm{AgCl}$ electrodes were used as counter and reference electrode, respectively. The following electrochemical procedure was applied: the sample was cycled (cyclic voltammetry, CV) under constant scan speed of $20 \mathrm{mV} / \mathrm{s}$ for 4 times $(-1.5$ to 1.0 $\mathrm{V}$ ). Afterward, the potential was held for $20 \mathrm{~h}$ at $-0.26 \mathrm{~V}$ (vs $\mathrm{Ag} / \mathrm{AgCl}$ ) (chronoamperometry, CA).

XRD measurements were performed on a Bruker D8 Advance (Da Vinci design with LynxEye detector, $\mathrm{Cu}$ radiation), equipped with a Göbel mirror and Eulerian cradle. The measurement range was set from 25 to $120^{\circ} 2 \theta$, with $0.02^{\circ}$ step size and $3 \mathrm{~s}$ counting time per step. The primary slit was chosen to be $0.6 \mathrm{~mm}$, the secondary soller was adjusted to $0.2^{\circ}$, and the incidence angle was set to $1^{\circ}$. Primary beam alignment was performed on $\theta$ and $2 \theta$ scale before each measurement using the glass-slit procedure. After 5, 10, and 15 $\mathrm{h}$ the measurement was repeated under the same conditions in order to monitor the changes. The in situ cell was used in foil cap (FC) mode with a Kapton foil ( $7.5 \mu$ m thickness) cap. The diffraction patterns were analyzed by full pattern fitting according to the Rietveld method using the Topas software (version 5, 1999-2014, Bruker AXS) in the range between 34 and $120^{\circ} 2 \theta$. Topas uses a convolution approach to synthesize the simulated diffraction pattern from instrumental and sample contributions. The instrumental contribution was determined beforehand using a corundum reference sample. The background of the diffraction patterns was refined in the fit, combining a second order Chebychev polynomial with a very broad (full width at half-maximum (fwhm): ca. $17^{\circ}$ ) Gaussian centered at $34^{\circ} 2 \theta$. The crystalline phases identified in the diffraction patterns were included in the respective fits. Please note: the Rietveld method is a technique to conduct quantitative phase and microstructure analysis of homogeneous powder samples, which are typically investigated with symmetric diffraction geometry.

\section{RESULTS}

Refraction Shift Correction for Flat Samples. Owing to the low incidence angle, the Bragg angle is shifted to a higher $2 \theta$ value, which is physically induced by the so-called refraction effect. The refraction effect occurs at incidence angles below $2^{\circ}$ at the interface of a solid and its environment. While reflections in XRD are defined by their intensity, position, and shape, the exact interpretation of these parameters in GIXRD require an additional treatment. ${ }^{21}$

When the incident beam passes through the boundaries of two different media with different refractive indices, the direction and wavelength are modified. This results in a shift of 
Table 1. Observed Results for Applying the Refraction Shift Correction to the Assembled in Situ Setup

\begin{tabular}{lccc} 
& $\delta$ & $\beta$ & $\alpha_{\mathrm{c}}$ \\
Cu 111 & $2.61 \times 10^{-5}$ & $5.13 \times 10^{-7}$ & $0.414^{\circ} / 0.0072 \mathrm{rad}$ \\
calculated $\Delta 2 \theta$ & & $0.089^{\circ}$ \\
experimental $\Delta 2 \theta$ & & $0.024^{\circ}$ \\
\hline
\end{tabular}

$2 \theta$ toward higher scattering angles. For symmetric scans the effect is negligibly small, whereas in GI geometry the shift can be in the range of a few tenths of degrees. To counterbalance this offset several reports have suggested corrections for the refraction shift. ${ }^{22,23}$ In GIXRD the correction factors are used to estimate the actual $2 \theta_{\text {Bragg }}$ values of thin films. In addition, thin films often exhibit a significant strain that depends on the method of deposition or the growth mechanism. For these samples reference values obtained from bulk samples are often not accurate enough to estimate the exact $d$-spacings. On the basis of the equation given by Toney et al. ${ }^{22}$ the refraction shift can be calculated for incidence angles $<2^{\circ}(1)$ :

$$
\Delta 2 \theta=\alpha-\frac{1}{\sqrt{2}} \sqrt{\left\{\sqrt{\left[\left(\alpha^{2}-\alpha_{c}^{2}\right)^{2}+4 \beta^{2}\right]}-\alpha_{c}^{2}+\alpha^{2}\right\}}
$$

$\alpha$ reflects the incidence angle, $\alpha_{\mathrm{c}}$ denotes the critical angle, and $\beta$ highlights the absorption term of the refractive index $n$. The dispersion term $\delta(\mathbf{2})$, the absorption term $\beta$ (4), and the critical angle can be calculated by eqs $2-5$ :

$$
\begin{gathered}
\delta=\frac{r_{0}}{2 \pi} \lambda^{2} \rho_{\mathrm{e}} \\
\rho_{\mathrm{e}}=\frac{\rho_{\mathrm{m}} N_{\mathrm{A}} Z}{A}
\end{gathered}
$$

$r_{0}$ is the classic electron radius, $\lambda$ denotes the wavelength of the X-rays, $\rho_{\mathrm{e}}$ is the electron density, $\rho_{\mathrm{m}}$ expresses the mass density, $N_{\mathrm{A}} Z$, and $A$ display the Avogadro number, atomic number, and mass number, respectively.

$$
\beta=\frac{\lambda}{4 \pi} \mu
$$

Here, $\mu$ denotes the linear attenuation coefficient.

$$
\alpha_{\mathrm{c}}=\sqrt{2 \delta}
$$

Table 1 summarizes the results obtained for the refraction shift correction of the copper sample for the $\mathrm{Cu} 111$ reflection. The calculated value is based on (1); the experimental shift was measured for the blank sample and is referenced to the actual $\mathrm{Cu} 111$ position (PDF 00-004-0836).

As shown in Table 1 the experimental value is significantly smaller than the calculated one. This discrepancy can be explained by a large deviation of the effective surface density $\left(2.4 \mathrm{~g} / \mathrm{cm}^{3}\right.$, recalculated from the experimental shift) to the nominal density $\left(8.9 \mathrm{~g} / \mathrm{cm}^{3}\right)$. This observed deviation is significantly influenced by the surface pretreatment (e.g., mechanical polishing). The refraction shift theory was derived for homogeneously flat surfaces and perfectly parallel interfaces. A high surface roughness ( $\mu \mathrm{m}$ range) would not allow for a homogeneous penetration of the surface and would lead to an experimental electron density lower than the nominal value. Furthermore, effects of the coherent scattering domain sizes on the refraction effect cannot be entirely excluded. $^{23}$
For the in situ electrochemical cell, the refractive shift is independent of the alignment procedure (Table 1) but depends crucially on the incidence angle. The highest refractive shifts were observed around $\alpha_{\mathrm{c}}$ (for $\mathrm{Cu} \alpha_{\mathrm{c}}=$ $\left.0.41^{\circ}\right)$. Around this critical angle the sensitivity of the evanescent wave traveling parallel along the sample surface is the highest for near-surface regions. At this angle the information depth for $\mathrm{Cu}$ is approximately $16 \mathrm{~nm}$. Continuous variation of the incident angle results in a depth resolved evaluation of the diffraction signal. It shall be noted that common polycrystalline samples will suffer from surface heterogeneities and enhanced diffuse scattering. The full potential of GIXRD (e.g., full depth profile) can, therefore, only be applied to a small fraction (e.g., multilayer semiconductors) of homogeneous samples. Nevertheless, this ultimate sensitivity is not always necessary to gain depth sensitive information, which renders our out-of-plane in situ GIXRD setup a useful technique for the study of polycrystalline surfaces.

Experimental Impact of the Electrochemical Setup on the Peak Intensity in the Diffractogram. GIXRD measurements reveal unique features of the surface composition. Generally, long penetration pathways would lead to an increase of the diffracted beam intensities. Figure 3 shows the

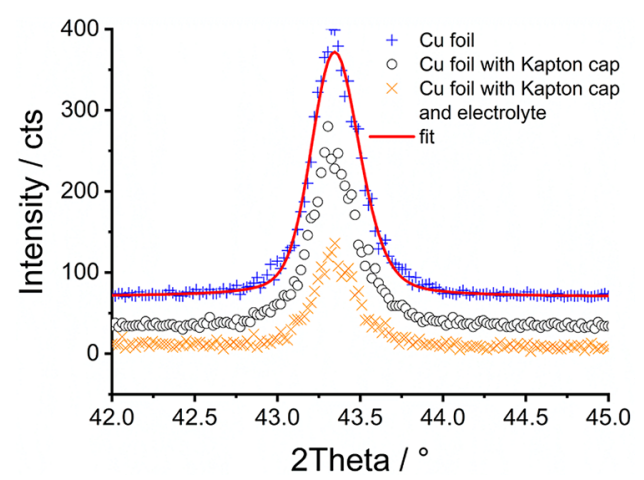

Figure 3. Measured intensities of the $\mathrm{Cu} 111$ reflection for different cell setups. For better visibility, the three curves are stacked along the $y$-direction. Blue pluses: blank $\mathrm{Cu}$ sample; black circles: sample with Kapton cap; orange crosses: sample with Kapton cap and electrolyte; red solid line: peak fitting (measurement parameters: $1^{\circ}$ incident angle, $3 \mathrm{~s}$ counting time, $0.02^{\circ}$ step size, and $0.6 \mathrm{~mm}$ slit size of the primary beam).

influence of the electrochemical setup on the intensities of the $\mathrm{Cu} 111$ reflection. Cap-free measurements on a $\mathrm{Cu}$ foil reveal the highest intensity for the 111 reflection. The reflection intensity decreases in the following order: blank > cap > cap + electrolyte. Variations of the electrolyte, caps, and samples influence the measured intensity directly. A quantitative description of the reflection intensity based on influencers, such as the cap and the electrolyte, is presented below.

The approximate path length (Table 2) through the cap and electrolyte can be evaluated by the mass attenuation 
Table 2. Calculated Path Lengths for the Observed Attenuation within the in Situ Setup

\begin{tabular}{|c|c|c|c|}
\hline & $\begin{array}{l}\text { intensity } \\
\text { (cts) }\end{array}$ & $\begin{array}{l}\text { path length }\left(\mathrm{H}_{2} \mathrm{O}\right) \\
\qquad(\mu \mathrm{m})\end{array}$ & $\begin{array}{c}\text { path length } \\
\text { (Kapton) }(\mu \mathrm{m})\end{array}$ \\
\hline blank & 330 & & \\
\hline + Kapton & 260 & & $\sim 275$ \\
\hline$+\underset{\text { electrolyte }}{\text { Kapton }+}$ & 130 & $\sim 350$ & $\sim 275$ \\
\hline
\end{tabular}

coefficients (Table 3 ). A recalculation can be performed by considering the ratio of initial $\left(I_{0}\right)$ and measured $(I)$ intensity:

Table 3. Mass Attenuation Coefficients (from NIST ${ }^{24}$ ) for Cu Radiation (8.07 keV)

$\begin{array}{lcc}\text { material } & \mu / \rho\left(\mathrm{cm}^{2} / \mathrm{g}\right) & \rho\left(\mathrm{g} / \mathrm{cm}^{3}\right) \\ \text { Mylar } & 6.75 & 1.38 \\ \text { PMMA } & 6.49 & 1.19 \\ \text { Kapton } & 3.1^{25} & 1.42 \\ \text { water } & 10.37 & 1.00\end{array}$

$$
I=I_{0} \mathrm{e}^{-(\mu / \rho) \rho d}
$$

The $\mu / \rho$ ratio reflects the mass attenuation coefficient $\left[\mathrm{cm}^{2} /\right.$ g]. $\rho$ is the density $\left[\mathrm{g} / \mathrm{cm}^{3}\right]$, and $d$ displays the path length $[\mathrm{cm}]$.

The path length of the Kapton foil (Table 2) differs strongly from its thickness of $7.5 \mu \mathrm{m}$. In GIXRD the beam travels almost horizontally along the foil rather than vertically. Moreover, this horizontal beam migration generates additional intensities which can be assigned to diffuse background scattering. Owing to the larger mass attenuation coefficient compared to the Kapton foil, the contribution of the water layer to the thickness (Table 3) is more significant. The calculated path length is based on the intensities of incoming and exiting beams. Since GI geometry is used, the attenuation of the incident beam is superior compared to the exit beam.

Quantification of the intensities can also be obtained by Rietveld refinement of the peak positions (Figure 3, red solid line) which results in integrated intensities. This way, the exact positions of the diffracted peaks and the fwhm are obtained for the $\mathrm{Cu} 111$ reflection in different setups (Table 4).

Table 4. Fitted Integral Intensity, $d$-Spacing and FWHM for Cu 111 during the Mounting Sequence

$\begin{array}{lccc} & \begin{array}{c}\text { integr. } \\ \text { intensity }\end{array} & d(\mathrm{Cu})(\AA) & \text { fwhm }(\mathrm{Cu} \mathrm{111}) \\ (\mathrm{deg})\end{array}$

The tabulated values in Table 4 agree with the trend of the attenuation calculation (Table 3). Additionally, the fwhm and $d$-spacing remain almost constant during the mounting sequence. The intensity change can, therefore, solely be attributed to the coverage of the sample by the cap and the electrolyte.

Cyclovoltammetric Measurements: Chemistry of Electrochemical Cu Oxidation. Many different techniques have been applied to study the oxidation of $\mathrm{Cu}$, and their results have led to controversial mechanisms. ${ }^{26-28}$ Oxidative reaction steps that involve the interplay between copper, its cations, and $\mathrm{OH}^{-}$ions have been introduced and are based on eqs $7-11:^{29,30}$

(1) Formation of $\mathrm{Cu}_{2} \mathrm{O}$ :

$$
2 \mathrm{Cu}+2 \mathrm{OH}^{-} \rightarrow \mathrm{Cu}_{2} \mathrm{O}+\mathrm{H}_{2} \mathrm{O}+2 \mathrm{e}^{-}
$$

(2) Formation of a porous cuprite layer and subsequent oxidative metal and/or cuprite dissolution: ${ }^{31,32}$

$$
\begin{aligned}
& \mathrm{Cu}+n \mathrm{OH}^{-} \rightarrow \mathrm{Cu}(\mathrm{OH})_{n}{ }^{2-n}+2 \mathrm{e}^{-} \\
& \mathrm{Cu}_{2} \mathrm{O}+\mathrm{H}_{2} \mathrm{O}+(2 n-2) \mathrm{OH}^{-} \\
& \rightarrow 2 \mathrm{Cu}(\mathrm{OH})_{n}{ }^{2-n}+2 \mathrm{e}^{-}
\end{aligned}
$$

(3) Formation of a temperature dependent $\mathrm{CuO}$ and $\mathrm{Cu}(\mathrm{OH})_{2}$ surface species: ${ }^{33}$

$$
\mathrm{Cu}(\mathrm{OH})_{n}{ }^{2-n} \rightarrow \mathrm{Cu}(\mathrm{OH})_{2}+(n-2) \mathrm{OH}^{-}\left(T<40^{\circ} \mathrm{C}\right)
$$

$$
\begin{aligned}
\mathrm{Cu}(\mathrm{OH})_{n}{ }^{2-n} & \rightarrow \mathrm{CuO}+(n-2) \mathrm{OH}^{-}+\mathrm{H}_{2} \mathrm{O}(T \\
& \left.>40^{\circ} \mathrm{C} \text {, energy }\right)
\end{aligned}
$$

A $\mathrm{CuO}$ passivation layer could form via precipitation and decomposition of the copper hydroxide species. The formation of this passivation layer depends on the selected potential range and temperature. ${ }^{31}$ Literature reports differ in the assignment of reactions $7-11$ to the corresponding peaks of the cyclovoltammograms (CV, Figure 4). The initial peak at

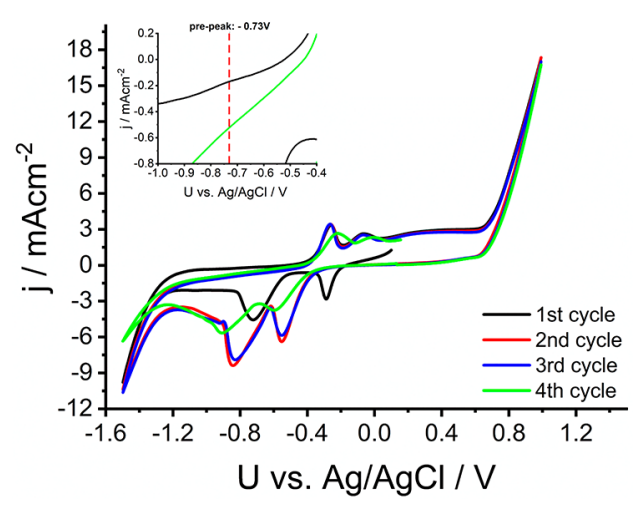

Figure 4. Recorded CV curves in $0.2 \mathrm{M} \mathrm{KOH}$ (Ar-purged) on a polycrystalline copper electrode (scan speed: $20 \mathrm{mV} / \mathrm{s}$ ) (black: first cycle; red: second cycle; blue: third cycle; green: fourth cycle).

$-0.68 \mathrm{~V}$ may act as an example. Ambrose et al. ${ }^{30}$ reported that at this potential the formation of soluble $\mathrm{Cu}(\mathrm{OH})_{2}$ species occurs prior to the typical bulk $\mathrm{Cu}_{2} \mathrm{O}$ formation at more positive potentials. Fletcher et al. ${ }^{34}$ assigned it to the dissolution of $\mathrm{Cu}^{+}$species, and $\mathrm{Miller}^{28}$ mentioned that for rotating disc experiments a direct dissolution of $\mathrm{Cu}$ as $\mathrm{Cu}_{2} \mathrm{O}$ cannot be observed. Finally, Droog et al. ${ }^{31}$ suggested that early stages of $\mathrm{Cu}$ oxidation are the electrosorption of oxygen species which is represented by a very small double peak at lower anodic potential.

In general, the $\mathrm{CV}$ curves of $\mathrm{Cu}$ in alkaline media exhibit six peaks that are situated between the electrochemical hydrogen and oxygen evolution reactions. ${ }^{35}$ On the anodic side four peaks can be identified which can partially overlap. In the 
cathodic regime mainly two peaks are observed. The anodic reactions toward the oxygen evolution reaction (OER) include electrosorption, formation of $\mathrm{Cu}_{2} \mathrm{O}$, and subsequent transformation into two $\mathrm{Cu}^{2+}$ species. ${ }^{31}$ In the cathodic regime two reactions dominate: the reduction of $\mathrm{Cu}^{2+}$ to $\mathrm{Cu}^{+}$and the complex and simultaneous reduction of $\mathrm{Cu}^{2+}$ to $\mathrm{Cu}^{0}$ and $\mathrm{Cu}^{+}$ to $\mathrm{Cu}^{0.23,29,32}$ The observed peak positions and charges depend strongly on the electrolyte concentration, scan speed, the chosen potential range, and the structure of the surface. $^{35,36}$

Cyclovoltammetric Measurements: Home-Built in Situ Setup. First Cycle. In Figure 4 the recorded CV scans for the home-built in situ setup are shown. Four main and two minor peaks can be observed after the first cycle. The oxidation peaks (positive amperage) are discussed with increasing positive potential. A prepeak is observed at $-0.73 \mathrm{~V}$, as seen in the inset of Figure 4. This prepeak can be assigned to the electrosorption of oxygen species. ${ }^{31,35}$ This observation could be explained by remaining nanostructured copper at the metallic $\mathrm{Cu}$ surfaces that may have survived the reductive pretreatment $(-1 \mathrm{~V}$ vs $\mathrm{Ag} / \mathrm{AgCl}$ for $10 \mathrm{~min})$. It has been shown that such nanostructured copper can be caused by an initial cleaning process, which is the reduction of native surface copper oxide to $\mathrm{Cu}^{37}$ Owing to the larger surface area of nanostructures, the adsorption of oxygen is enhanced.

Two peaks at approximately $-0.26 \mathrm{~V}$ and $-0.06 \mathrm{~V}$, which are almost constant during electrochemical cycling, are ascribed to the formation of $\mathrm{Cu}_{2} \mathrm{O}$ and $\mathrm{CuO} / \mathrm{Cu}(\mathrm{OH})_{2}$, respectively. ${ }^{35}$ The broad peak located at approximately +0.32 $\mathrm{V}$ may indicate a slow hydroxylation of $\mathrm{CuO}$. This peak is more pronounced in the first cycle and may also point to the presence of a nanostructured $\mathrm{Cu}$ surface, which can be dissolved by the formation of tetrahydroxycuprate (II) $\left(\mathrm{Cu}(\mathrm{OH})_{4}{ }^{2-}\right)$ anions.

In the reduction regime (negative amperage) peaks are found at $-0.28 \mathrm{~V}$ and $-0.72 \mathrm{~V}$, respectively (Figure 4). The peak at approximately $-0.28 \mathrm{~V}$ corresponds to the decomposition of dissolved $\mathrm{Cu}(\mathrm{OH})_{4}{ }^{2-}$ species to $\mathrm{CuO}$, which can homogeneously line the surface of the substrate. ${ }^{36}$ Simultaneously the partial reduction of $\mathrm{Cu}^{2+}$ to $\mathrm{Cu}_{2} \mathrm{O}$ can also occur. $^{26,30,35}$ At more negative potential a complex reduction network involving the concurrent reduction of $\mathrm{Cu}^{2+}$ species and $\mathrm{Cu}_{2} \mathrm{O}$ to metallic $\mathrm{Cu}$ takes place. ${ }^{30,36}$

Multiple Cycling. For additional cycles, significant peak shifts and differences in the peak area can be observed (Figure 4). In the second cycle, the two main oxidation peaks remain almost constant, whereas the two peaks in the reduction regime exhibit a significant shift to $-0.55 \mathrm{~V}$ and $-0.79 \mathrm{~V}$, respectively. The shift may originate from initial surface cleaning, which would then remove the nanostructured $\mathrm{Cu}$ surface. Thus, owing to the lower surface area, in the second cycle, less dissolvable hydroxylated $\mathrm{Cu}^{2+}$ species may be formed. The surface is, therefore, enriched in $\mathrm{CuO} / \mathrm{Cu}_{2} \mathrm{O}$ and requires more energy for the reduction. Consequently, the first reduction peak is shifted to more negative potential. In addition, monoelectronic reduction to $\mathrm{Cu}_{2} \mathrm{O}$ might be also hampered. ${ }^{30,36}$ The variation of the peak area between the first and the second scan can be further influenced by the $\mathrm{OH}^{-}$ concentration. From the second to the third cycle, almost no changes can be observed. The electrochemical cycling may cause a flattening of the metallic $\mathrm{Cu}$ surface. In addition, domain growth can also occur.
In the fourth cycle, a drastic peak shift can be observed. OER is part of all cycles and, thus, small amounts of molecular oxygen are released. Its solubility and diffusivity have an essential influence which can be observed by the slight decrease of the oxygen reduction current. This effect changes the concentration of surface $\mathrm{OH}^{-}$ions and causes probably the shift of approximately $0.05 \mathrm{~V} \cdot{ }^{35,36}$ In addition, the unstirred electrolyte can influence the diffusivity, which results in local concentration gradients. Diffusion limitations may further be caused by a tight foil arrangement over the reactive $\mathrm{Cu}$ surface.

Electrochemical Surface Oxidation and in Situ GIXRD Measurements. An isodynamic, long-term experiment was conducted for $20 \mathrm{~h}$ at $-0.26 \mathrm{~V}$ to study time-dependent details of the oxidation of metallic $\mathrm{Cu}$. Figure 5 shows the

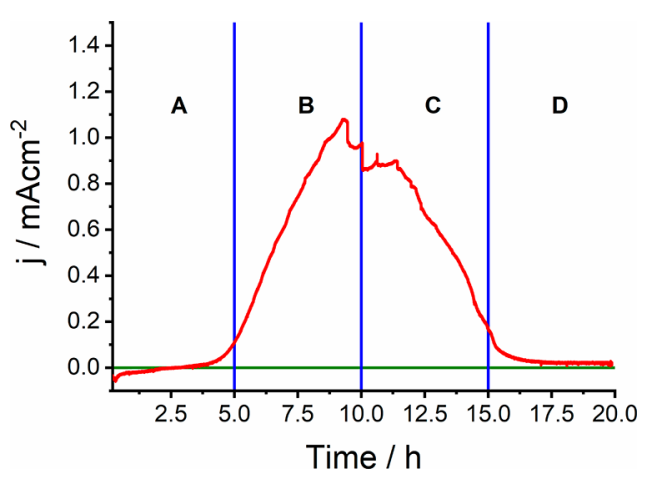

Figure 5. Chronoamperometry curve $(20 \mathrm{~h} @-0.26 \mathrm{~V})$ of the polycrystalline copper electrode in $0.2 \mathrm{M} \mathrm{KOH}$. The green line corresponds to $0 \mathrm{~mA} \mathrm{~cm}{ }^{-1}$. The blue vertical lines denote the different regimes.

corresponding chronoamperometric (CA) curve. The oxidation potential was set at the peak assigned to the occurrence of $\mathrm{Cu}^{+}$species in the $\mathrm{CV}$. The CA curve is split into four regions (Figure 5A-D). The CA measurements allow for identifying in situ transient species in the time-dependent $\mathrm{Cu}$ oxidation by GIXRD measurement (Figure 6). In addition, Rietveld refined analyses of the diffraction patterns are presented in Figure 7.

Regime A. Initially, the current is still in the cathodic regime (Figure 5, region A), while only reflections which can be attributed to metallic $\mathrm{Cu}$ can be observed in the in situ GIXRD measurements (Figure 6, black curve, Figure 7a). Furthermore, the GIXRD measurements show that the intensities of the reflections that can be attributed to metallic $\mathrm{Cu}$ increase during the CA experiment in region A (Table 5, Figure 6, red curve, Figure $7 \mathrm{~b}$ ). This suggests a cleaning of the surface or that some $\mathrm{X}$-ray amorphous oxidized $\mathrm{Cu}$ species could have survived the electrochemical cycling and are reduced at this potential.

The initial reduction process may, thus, lead to surface healing and defines the $\mathrm{Cu}$ domains. After approximately $2.5 \mathrm{~h}$ the sign of the current changes (Figure 5, region A) suggesting the oxidation of the $\mathrm{Cu}$ surface. In situ GIXRD measurement after $5 \mathrm{~h}$ (Figure 6, red curve, Figure 7b) shows a small but significant diffraction peak assignable to $\mathrm{Cu}_{2} \mathrm{O}$. The formation of $\mathrm{Cu}_{2} \mathrm{O}$ can occur by disturbing the equilibrium conditions of deposited $\mathrm{Cu}(\mathrm{OH})_{2}$ at the surface and soluble $\mathrm{Cu}(\mathrm{OH})_{4}{ }^{2-}$ (10) species which can than react according to (9) via a local supersaturation to porous cuprite species. In addition, local supersaturation may also drive the reaction toward the direct oxidation of $\mathrm{Cu}$ to $\mathrm{Cu}_{2} \mathrm{O}$ (7). Altogether, the observation of the occurrence of an initial reduction process and subsequent 

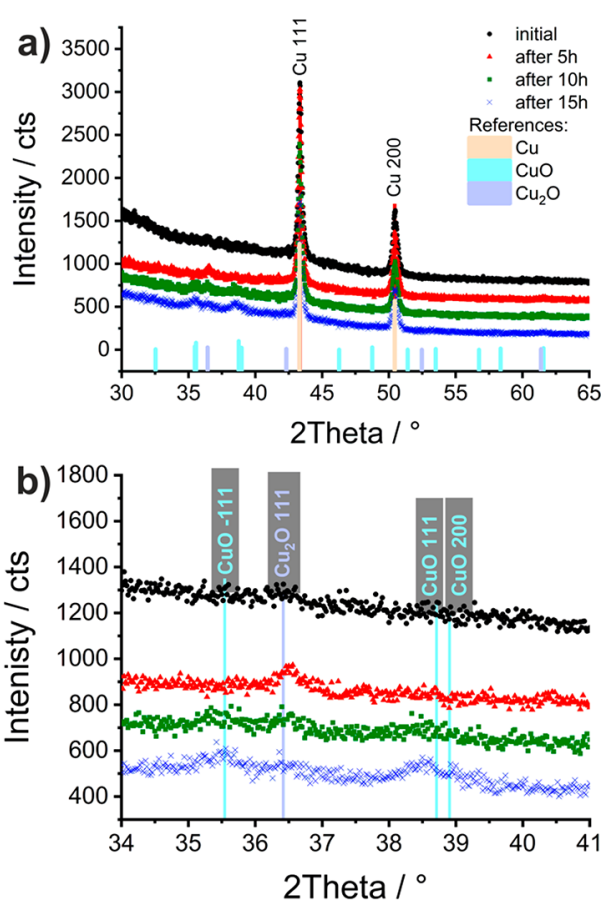

Figure 6. In situ GIXRD data recorded at different times during the oxidation of polycrystalline $\mathrm{Cu}$ in $0.2 \mathrm{M} \mathrm{KOH}$. The four curves are stacked along the y-direction. (b) Magnified $2 \theta$ regime in which the cuprite/tenorite evolution can be followed (black spheres: initial; red triangles: after $5 \mathrm{~h}$; green squares: after $10 \mathrm{~h}$; blue crosses: after $15 \mathrm{~h}$ ). Main reflections are indicated; phases: $\mathrm{Cu}$ : PDF 00-004-0836; $\mathrm{Cu}_{2} \mathrm{O}$ : PDF 04-007-9767; CuO: PDF 04-007-1375.

reoxidation may be supported by the higher intensity of the $\mathrm{Cu}$ reflections in the GIXRD measurements after $5 \mathrm{~h}$ compared to
Table 5. Fitted Integral Intensities and FWHM for $\mathrm{Cu} 111$ and $\mathrm{Cu} 200$ during the CA Treatment ${ }^{a}$

$\begin{array}{lcccc} & \text { Int(111) } & \text { Int(200) } & \begin{array}{c}\text { fwhm(111) } \\ (\mathrm{deg})\end{array} & \begin{array}{c}\text { fwhm(200) } \\ (\mathrm{deg})\end{array} \\ \text { start } & 205 \pm 5 & 105 \pm 5 & 0.16 \pm 0.05 & 0.34 \pm 0.03 \\ \text { after 5 h } & 229 \pm 5 & 109 \pm 5 & 0.17 \pm 0.04 & 0.36 \pm 0.03 \\ \text { after 10 h } & 175 \pm 4 & 83 \pm 5 & 0.16 \pm 0.04 & 0.35 \pm 0.03 \\ \text { after 15 h } & 136 \pm 4 & 66 \pm 4 & 0.17 \pm 0.04 & 0.35 \pm 0.03\end{array}$

${ }^{a_{T}}$ The error intervals correspond to \pm 3 esd (estimated standard deviations) provided by the fit algorithm.

the initial intensity (Table 5). Moreover, the significant decrease of the diffuse scattering background after $5 \mathrm{~h}$ corroborates the assumption that X-ray amorphous surface species may have been present at the initial stage.

Regime $B$. The oxidation of copper under constant potential is expected to continue until species have been formed which are stable under the current load governed by the local chemical potential. Furthermore, the porous cuprite layer which is a semiconducting oxide can be partially oxidized into soluble $\mathrm{Cu}(\mathrm{OH})_{4}{ }^{2-}$ species (9). This can enhance the ion concentration in the electrolyte and, thus, the electrical conductivity, which leads to the observed increase of the current (Figure 5, regime $\mathrm{B}$ ). As a possible side reaction the partial dehdroxylation of the $\mathrm{Cu}(\mathrm{OH})_{4}{ }^{2-}$ anion to $\mathrm{Cu}(\mathrm{OH})_{2}$ (10) could be discussed, which can be further dehydrated to $\mathrm{CuO}$ (11). $\mathrm{CuO}$ accumulates continuously at the surface. In line, the in situ GIXRD measurement shows a decay of the intensity of the metallic $\mathrm{Cu}$ and cuprite reflections (Figure 6, green curve, Figure $7 c$, Table 5). In addition, they are accompanied by the appearance of weak $\mathrm{CuO}$ reflections. Generally, the conversion of cuprite to $\mathrm{Cu}(\mathrm{OH})_{2}$ takes place at more positive potentials (in our $\mathrm{CV}$ assumed at $\sim-0.06 \mathrm{~V}$ ).
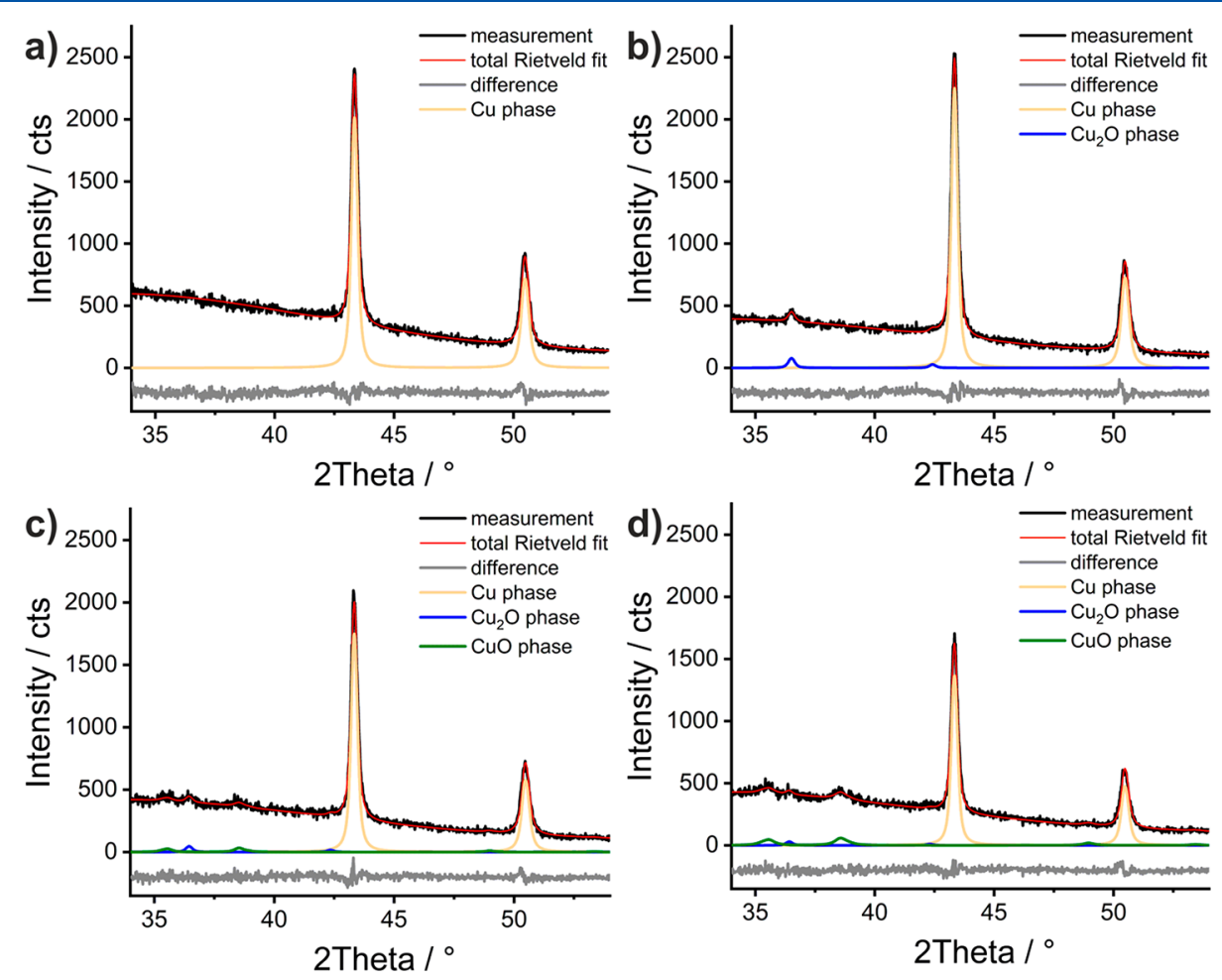

Figure 7. Rietveld fits of the in situ GIXRD data recorded at different times during the oxidation of polycrystalline Cu in $0.2 \mathrm{M} \mathrm{KOH}$ : (a) initial, (b) after $5 \mathrm{~h},(\mathrm{c})$ after $10 \mathrm{~h},(\mathrm{~d})$ after $15 \mathrm{~h}$. 


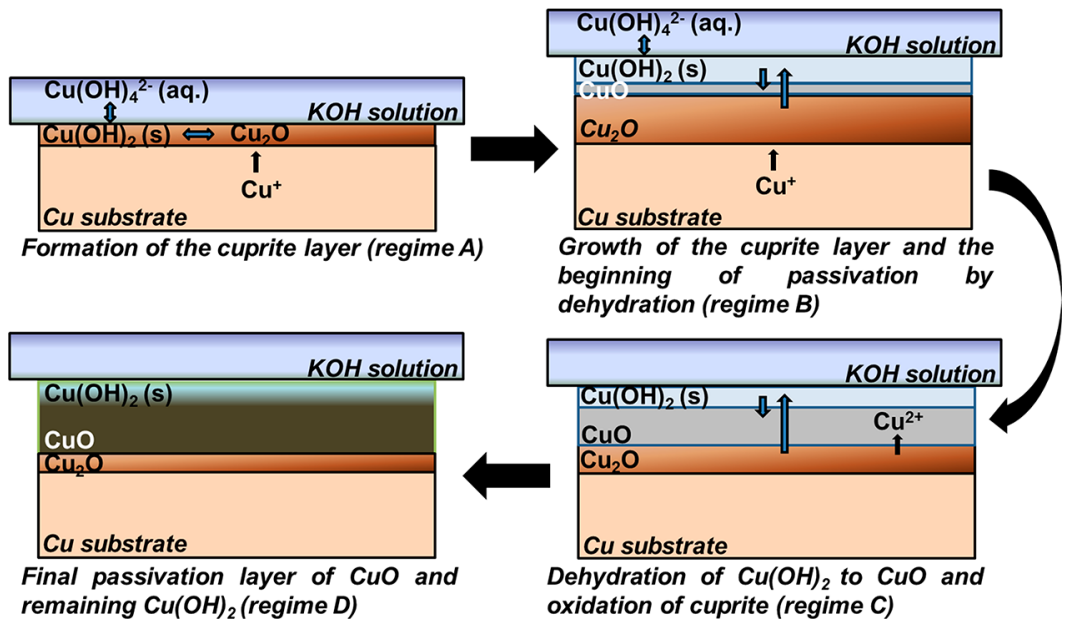

Figure 8. Schematic drawing that highlights the proposed pathway of the formation of the passivation layer.

Thus, the intermediate formation of $\mathrm{Cu}_{2} \mathrm{O}$ under constant oxidation potential, and its subsequent, but indirect transformation into $\mathrm{CuO}$, indicates a thermodynamically driven reaction pathway.

Regime $C$ and $D$. At a certain point, the concentration of dissolved $\mathrm{Cu}(\mathrm{OH})_{4}{ }^{2-}$ species decreases, which results in the reduction of the electrical conductivity of the electrolyte and the partial dehydroxylation to X-ray amorphous $\mathrm{Cu}(\mathrm{OH})_{2}$. This situation is met after $10 \mathrm{~h}$, as demonstrated by the decreasing current and the inflection point in Figure 5 (regime C). Small spontaneous current drops at the reversal point indicate the beginning of the surface passivation, and the formation of increasing amounts of $\mathrm{CuO}$. After $15 \mathrm{~h}$, the in situ GIXRD measurement indicates (Figure 6, blue curve, Figure $7 \mathrm{~d})$ that the electrical isolating tenorite phase becomes more prominent. Furthermore, the intensity of the reflection that corresponds to cuprite decreases slightly (Figure 6b, Figure $7 \mathrm{~d}$ ). Note, whether this decrease is caused by actual consumption of the cuprite phase, or simply by the ongoing overgrowth by the tenorite layer, cannot entirely be deduced from our data. Finally in area D, the current stays at zero indicating the complete surface passivation, which hampers electron transfer. The formation of an oxidic surface layer can also be observed by the darkening of the sample which is typical for tenorite (Figure S3).

In Situ GIXRD Measurements. The in situ GIXRD measurements shown above (Figure 6 and Figure 7) are a first proof of the proposed reaction pathway. While the intensities of the $\mathrm{Cu}$ reflections tend to change with the oxidative treatment, the fwhm remains constant within the error of the measurements (Table 5). The decrease of the intensity for the sample after 10 and $15 \mathrm{~h} \mathrm{CA}$ treatment is in line with the stepwise surface oxidation and the growth of a surface passivation layer. A possible $\mathrm{Cu}(\mathrm{OH})_{2}$ species cannot be observed in our in situ measurements. ${ }^{30,38}$ The absence of $\mathrm{Cu}(\mathrm{OH})_{2}$ peaks suggest an amorphous or hydrated surface species, which is invisible for GIXRD. Ex situ phase analysis demonstrated that after electrochemical treatment in alkaline media a crystalline $\mathrm{Cu}(\mathrm{OH})_{2}$ is present on the surface. ${ }^{29}$ In addition, the alkaline experimental conditions $\mathrm{Cu}(\mathrm{OH})_{2}$ is soluble and may be dissolved as $\mathrm{Cu}(\mathrm{OH})_{4}{ }^{2-}$ species. $^{39}$ This highlights the importance of investigating chemical transformations by in situ techniques in order to extract realistic models. Moreover, the weak intensities of the $\mathrm{CuO}$ and $\mathrm{Cu}_{2} \mathrm{O}$ reflections can be related to surface layers that can also consist of additional amorphous compounds. Further, details on the film structure cannot be interpreted by the GIXRD measurements due to the possible presence of X-ray amorphous phases.

\section{DISCUSSION}

The results obtained by this in situ GIXRD study clearly showed the feasibility of this approach obtained by a common laboratory X-ray source. As opposed to cell designs that are reported in the literature, ${ }^{40-42}$ our three electrodes and chemically inert setup was constructed to enable maximum flexibility and surface sensitivity for laboratory X-ray diffractometers. This includes the compatibility of an Eulerian cradle and the possibility to investigate single and polycrystalline samples. This flexibility is of paramount importance as, for instance, the majority of samples in the chemical laboratory are polycrystalline. In addition, an electrochemical setup for laboratory sources has also been reported; however, it was constructed such that only symmetric XRD measurements are possible. $^{43}$

The combination of electrochemical treatment with a timedependent diffraction study revealed details on the oxidation mechanism of $\mathrm{Cu}$ from early points of cuprite formation to the complete surface passivation. The good agreement between GIXRD and electrochemistry allowed us to conclude the details of a working solid-liquid interface.

The observed peak shifts within the four $\mathrm{CV}$ cycles and the assumed strong dependency on the $\mathrm{OH}^{-}$concentration are in accordance with previous experiments. ${ }^{35}$ In addition, the observations of a crystalline $\mathrm{Cu}_{2} \mathrm{O}$ intermediate under constant current conditions, as well as the identification of $\mathrm{CuO}$ as one of the main component of the passivation layer highlights the importance of this in situ characterization. A crystalline $\mathrm{Cu}_{2} \mathrm{O}$ intermediate during the electrochemical oxidation of polycrystalline $\mathrm{Cu}$ in $\mathrm{KOH}$ has yet not been directly evidenced by in situ laboratory XRD measurements but has been proposed from electrochemical cycling experiments before. ${ }^{29-31}$ Previous in situ XPS and single crystal diffractometric experiments on synchrotrons are in line with our observation. ${ }^{44,45}$

The complexity even for a comparably simple oxidation experiment could be unveiled. The in situ GIXRD and CA data suggest that the $\mathrm{Cu}$ oxidation process is driven by $\mathrm{OH}^{-}$ concentration and depends on the position of the equilibrium in an environment in which simultaneously multiple chemical 
reactions can occur. The change in the local chemical potential goes hand in hand with the shift of the electrical conductivity. Growth kinetics and supersaturation seem to drive the crystallization and oxidation process (Figures 5 and 6). In addition, $\mathrm{Cu}(\mathrm{OH})_{2}$ is invisible for GIXRD during our applied in situ conditions. Its presence cannot be excluded by XRD measurements. A schematic drawing of the proposed reaction pathway from its origin to passivation is given in Figure 8.

The assumed layered nature of our sample system (Figure 8) can, however, lead to an intensity bias. This bias would favor the intensity distribution of the upper layer over the lower layer. This effect is even more pronounced in the applied GI geometry and depends on the incidence angle as well as the absorption coefficient of the involved materials. Finally, texture effects (i.e., nonrandom crystallite orientation) can affect the relative intensities and cannot be excluded in our system. These factors prevent any further quantitative interpretation of our Rietveld fits. Nevertheless, the fits show the temporal evolution (i.e., appearance/disappearance) of the $\mathrm{Cu}_{2} \mathrm{O}$ and $\mathrm{CuO}$ phases. In addition, lower intensities, limitation in the collimation of the X-ray beam and larger wavelength compared to synchrotron radiation may limit laboratory X-ray diffractometers for GIXRD measurements. Nevertheless, such laboratory in situ GIXRD setups can be used as screening devices to elucidate structural dynamics and reaction conditions. Subsequently detailed investigation can be done at selected samples at synchrotrons. The GIXRD results obtained with our laboratory diffractometer form, thus, a sound base for the investigation of surface processes.

The possibility to simultaneously conduct in situ diffraction and electrochemical experiments by our laboratory X-ray source, equipped with a home-built in situ setup, may act as an example of how fundamental research on chemical reactions in the laboratory can be prospectively conducted.

\section{CONCLUSION}

In summary, this study demonstrates that the surface of a sample exposed to an electrochemical relevant environment can be measured by in situ out-of-plane GIXRD investigations. In addition, the obtained diffractograms exhibit sufficient intensity for fitting, and conclusions on the temporal evolution of the involved crystalline phases can be extracted. Even though the main reflections of the oxides are barely larger than the noise amplitude, the Rietveld fits help to demonstrate their temporal evolution. The designed in situ electrochemical cell renders a common laboratory diffractometer into a powerful in situ machine. In addition, we suppose that the cell is multifunctional and may be applied for different complementary operando techniques, such as Raman spectroscopy. Prospectively, the cell can be augmented to establish a flow system, which would allow for detecting possible dissolved species, for monitoring reaction products, and for maintaining steady-state conditions. The in situ investigation of the electrochemical oxidation of $\mathrm{Cu}$ revealed the stepwise formation of $\mathrm{CuO}$ films on the surface. The observation of a crystalline $\mathrm{Cu}_{2} \mathrm{O}$ intermediate further highlights the benefit of combining electrochemistry with integral surface-sensitive, in situ laboratory-based GIXRD measurements. Furthermore, the observed changes in the GIXRD patterns are in good agreement with the changes observed in the electrochemical experiment, which gives rise to an artifact-poor analysis of working interfaces. It is expected that this combination can potentially be extended to investigate more complex surface modifications of electrodes during electrocatalysis or reactions such as OER.

\section{ASSOCIATED CONTENT}

\section{S Supporting Information}

The Supporting Information is available free of charge on the ACS Publications website at DOI: 10.1021/acs.jpcc.9b00282.

Image of mounted setup, details of the sample holder, and image of optical changes during the electrochemical treatment (PDF)

\section{AUTHOR INFORMATION}

\section{Corresponding Author}

*E-mail: lunkenbein@fhi-berlin.mpg.de.

ORCID

Marc-Georg Willinger: 0000-0002-9996-7953

Elias Frei: 0000-0003-3565-1199

Thomas Lunkenbein: 0000-0002-8957-4216

\section{Notes}

The authors declare no competing financial interest.

\section{REFERENCES}

(1) Zegenhagen, J.; Renner, F. U.; Reitzle, A.; Lee, T. L.; Warren, S.; Stierle, A.; Dosch, H.; Scherb, G.; Fimland, B. O.; Kolb, D. M. In situ $\mathrm{X}$-ray analysis of solid/electrolyte interfaces: electrodeposition of $\mathrm{Cu}$ and $\mathrm{Co}$ on $\mathrm{Si}(111): \mathrm{H}$ and $\mathrm{GaAs}(001)$ and corrosion of $\mathrm{Cu} 3 \mathrm{Au}(111)$. Surf. Sci. 2004, 573, 67-79.

(2) Nikolaenko, A.; Kovalchuk, M.; Shilin, Y.; Ermolaev, A.; Bobrovski, S.; Chaplygin, G. UHV systems for X-ray diffraction experiments with conventional and synchrotron radiation sources. Phys. B 1994, 198, 228-230.

(3) Renner, F. U.; Gründer, Y.; Zegenhagen, J. Portable chamber for the study of UHV prepared electrochemical interfaces by hard X-ray diffraction. Rev. Sci. Instrum. 2007, 78, 033903.

(4) Russell, A. E.; Maniguet, S.; Mathew, R. J.; Yao, J.; Roberts, M. A.; Thompsett, D. In situ X-ray absorption spectroscopy and X-ray diffraction of fuel cell electrocatalysts. J. Power Sources 2001, 96, 226232.

(5) Samant, M. G.; Toney, M. F.; Borges, G. L.; Blum, L.; Melroy, O. R. In-situ grazing incidence X-ray diffraction study of electrochemically deposited Pb monolayers on $\mathrm{Ag}(111)$. Surf. Sci. 1988, 193, L29-L36.

(6) Pietsch, U. Investigations of semiconductor surfaces and interfaces by X-ray grazing incidence diffraction. Curr. Sci. 2000, 78, $1484-1495$

(7) Schuster, M.; Gobel, H. Parallel-beam coupling into channel-cut monochromators using curved graded multilayers. J. Phys. D: Appl. Phys. 1995, 28, A270-A275.

(8) Marra, W. C.; Eisenberger, P.; Cho, A. Y. X-ray total-externalreflection-Bragg diffraction: A structural study of the GaAs-Al interface. J. Appl. Phys. 1979, 50, 6927-6933.

(9) Robinson, K. M.; O'Grady, W. E. X-ray surface diffraction studies of the restructuring and electrodeposition of $\mathrm{Pb}$ monolayers on $\mathrm{Au}(100)$ single crystals. Faraday Discuss. 1993, 95, 55-64.

(10) Melroy, O. R.; Toney, M. F.; Borges, G. L.; Samant, M. G.; Kortright, J. B.; Ross, P. N.; Blum, L. Two-dimensional compressibility of electrochemically adsorbed lead on silver (111). Phys. Rev. B: Condens. Matter Mater. Phys. 1988, 38, 10962-10965.

(11) Stojek, Z. In Electroanalytical Methods: Guide to Experiments and Applications; Scholz, F.; Bond, A. M.; Compton, R. G.; Fiedler, D. A.; Inzelt, G.; Kahlert, H.; Komorsky-Lovrić, S.; Lohse, H.; Lovrić, M.; Marken, F.; et al., Eds.; Springer: Berlin, 2010; pp 3-9.

(12) Magnussen, O. M. Ordered Anion Adlayers on Metal Electrode Surfaces. Chem. Rev. 2002, 102, 679-726. 
(13) Keller, H.; Saracino, M.; Nguyen, H. M. T.; Broekmann, P. Templating the near-surface liquid electrolyte: In situ surface $\mathrm{x}$-ray diffraction study on anion/cation interactions at electrified interfaces. Phys. Rev. B: Condens. Matter Mater. Phys. 2010, 82, 245425.

(14) Müller, E. Über Passives Kupfer, Bezw. Das Anodische Verhalten des Kupfers in Natronlauge. Z. Elektrochem. Angew. Phys. Chem. 1907, 13, 133-145.

(15) Roy, B. N.; Wright, T. Electrical conductivity in polycrystalline copper oxide thin films. Cryst. Res. Technol. 1996, 31, 1039-1044.

(16) Gao, D.; McCrum, I. T.; Deo, S.; Choi, Y.-W.; Scholten, F.; Wan, W.; Chen, J. G.; Janik, M. J.; Roldan Cuenya, B. Activity and selectivity control in $\mathrm{CO}_{2}$ electroreduction to multicarbon products over $\mathrm{CuO}_{\mathrm{x}}$ catalysts via electrolyte design. ACS Catal. 2018, 8, $10012-10020$.

(17) Klingan, K.; Kottakkat, T.; Jovanov, Z. P.; Jiang, S.; Pasquini, C.; Scholten, F.; Kubella, P.; Bergmann, A.; Roldan Cuenya, B.; Roth, C.; et al. Reactivity determinants in electrodeposited $\mathrm{Cu}$ foams for electrochemical $\mathrm{CO}_{2}$ reduction. ChemSusChem 2018, 11, 3449-3459.

(18) Velasco-Vélez, J.-J.; Jones, T.; Gao, D.; Carbonio, E.; Arrigo, R.; Hsu, C.-J.; Huang, Y.-C.; Dong, C.-L.; Chen, J.-M.; Lee, J.-F.; et al. The role of the copper oxidation state in the electrocatalytic reduction of $\mathrm{CO}_{2}$ into valuable hydrocarbons. ACS Sustainable Chem. Eng. 2019, 7, 1485-1492.

(19) Velasco-Vélez, J.-J.; Skorupska, K.; Frei, E.; Huang, Y.-C.; Dong, C.-L.; Su, B.-J.; Hsu, C.-J.; Chou, H.-Y.; Chen, J.-M.; Strasser, P.; et al. The electro-deposition/dissolution of $\mathrm{CuSO}_{4}$ aqueous eectrolyte investigated by in situ soft X-ray absorption spectroscopy. J. Phys. Chem. B 2018, 122, 780-787.

(20) Arun, A.; Gupta, C.; Howe, R. Polyether ether ketone (PEEK) fluidic cell to study electrochemistry of microelectrodes on silicon substrate. ECS Solid State Lett. 2015, 4, P67-P71.

(21) Fewster, P. F. Reciprocal space mapping. Crit. Rev. Solid State Mater. Sci. 1997, 22, 69-110.

(22) Toney, M. F.; Brennan, S. Observation of the effect of refraction on $\mathrm{X}$ rays diffracted in a grazing-incidence asymmetric Bragg geometry. Phys. Rev. B: Condens. Matter Mater. Phys. 1989, 39, 7963-7966.

(23) Lim, G.; Parrish, W.; Ortiz, C.; Bellotto, M.; Hart, M. Grazing incidence synchrotron X-ray diffraction method for analyzing thin films. J. Mater. Res. 1987, 2, 471-477.

(24) Hubbel, J. H.; Seltzer, S. M. Tables of X-ray Mass Attenuation Coefficients and Mass Energy-Absorption Coefficients, version 1.4; http://physics.nist.gov/xaamdi [2019, March 25]. National Institute of Standards and Technology: Gaithersburg, MD, 2004.

(25) Angelone, M.; Esposito, A.; Chiti, M.; Gentile, A. Measurement of mass attenuation coefficients for four mixtures using X-rays from 13 $\mathrm{keV}$ up to $40 \mathrm{keV}$. Radiat. Phys. Chem. 2001, 61, 547-548.

(26) Pyun, C. H.; Park, S. M. In situ spectroelectrochemical studies on anodic oxidation of copper in alkaline solution. J. Electrochem. Soc. 1986, 133, 2024-2030.

(27) Strehblow, H. H.; Titze, B. The investigation of the passive behaviour of copper in weakly acid and alkaline solutions and the examination of the passive film by esca and ISS. Electrochim. Acta 1980, 25, 839-850.

(28) Miller, B. Split-ring disk study of the anodic processes at a copper electrode in alkaline solution. J. Electrochem. Soc. 1969, 116, $1675-1680$.

(29) He, J.-B.; Lu, D.-Y.; Jin, G.-P. Potential dependence of cuprous/cupric duplex film growth on copper electrode in alkaline media. Appl. Surf. Sci. 2006, 253, 689-697.

(30) Ambrose, J.; Barradas, R. G.; Shoesmith, D. W. Investigations of copper in aqueous alkaline solutions by cyclic voltammetry. $J$. Electroanal. Chem. Interfacial Electrochem. 1973, 47 (1), 47-64.

(31) Droog, J. M. M.; Alderliesten, C. A.; Alderliesten, P. T.; Bootsma, G. A. Initial stages of anodic oxidation of polycrystalline copper electrodes in alkaline solution. J. Electroanal. Chem. Interfacial Electrochem. 1980, 111, 61-70.

(32) Dignam, M. J.; Gibbs, D. B. Anodic oxidation of copper in alkaline solution. Can. J. Chem. 1970, 48, 1242-1250.
(33) Shoesmith, D. W.; Sunder, S.; Bailey, M. G.; Wallace, G. J.; Stanchell, F. W. Anodic oxidation of copper in alkaline solutions: Part IV. Nature of the passivating film. J. Electroanal. Chem. Interfacial Electrochem. 1983, 143, 153-165.

(34) Fletcher, S.; Barradas, R. G.; Porter, J. D. The anodic oxidation of copper amalgam and polycrystalline copper electrodes in $\mathrm{LiOH}$ solution. J. Electrochem. Soc. 1978, 125, 1960-1968.

(35) Dong, S.; Xie, Y.; Cheng, G. Cyclic voltammetric and spectroelectrochemical studies of copper in alkaline solution. Electrochim. Acta 1992, 37, 17-22.

(36) Abd el Haleem, S. M.; Ateya, B. G. Cyclic voltammetry of copper in sodium hydroxide solutions. J. Electroanal. Chem. Interfacial Electrochem. 1981, 117, 309-319.

(37) Zhang, W.; Wen, X.; Yang, S. Controlled reactions on a copper surface: synthesis and characterization of nanostructured copper compound films. Inorg. Chem. 2003, 42, 5005-5014.

(38) Shoesmith, D. W.; Rummery, T. E.; Owen, D.; Lee, W. Anodic oxidation of copper in alkaline solutions: I. Nucleation and growth of cupric hydroxide films. J. Electrochem. Soc. 1976, 123, 790-799.

(39) Giri, S. D.; Sarkar, A.; Mahajani, S.; Suresh, A. K. Electrochemical reduction of $\mathrm{CO}_{2}$ on copper oxidized by electrochemical methods. ECS Trans. 2017, 75, 19-31.

(40) Herron, M. E.; Doyle, S. E.; Roberts, K. J.; Robinson, J.; Walsh, F. C. Instrumentation and cell design for in situ studies of electrode surfaces using X-ray synchrotron radiation. Rev. Sci. Instrum. 1992, 63, 950-955.

(41) Koop, T.; Schindler, W.; Kazimirov, A.; Scherb, G.; Zegenhagen, J.; Schulz, T.; Feidenhans'l, R.; Kirschner, J. Electrochemical cell for in situ $\mathrm{x}$-ray diffraction under ultrapure conditions. Rev. Sci. Instrum. 1998, 69, 1840-1843.

(42) Ocko, B. M.; Wang, J.; Davenport, A.; Isaacs, H. In situ X-ray reflectivity and diffraction studies of the $\mathrm{Au}(001)$ reconstruction in an electrochemical cell. Phys. Rev. Lett. 1990, 65, 1466-1469.

(43) Chabanier, C.; Guay, D. Activation and hydrogen absorption in thermally prepared $\mathrm{RuO}_{2}$ and $\mathrm{IrO}_{2}$. J. Electroanal. Chem. 2004, 570, $13-27$.

(44) Chu, Y. S.; Robinson, I. K.; Gewirth, A. A. Comparison of aqueous and native oxide formation on $\mathrm{Cu}(111)$. J. Chem. Phys. 1999, $110,5952-5959$.

(45) Wan, Y.; Zhang, Y.; Wang, X.; Wang, Q. Electrochemical formation and reduction of copper oxide nanostructures in alkaline media. Electrochem. Commun. 2013, 36, 99-102. 